ELEMENTARY ENGINEERING MECHANICS 
Other title by the same author

Applied Mechanics Made Simple (Heinemann: 'Made Simple' series)

Other Macmillan titles of related interest

Basic Engineering Mechanics J. H. Hughes and K. F. Martin

Engineering Mathematics, second edition K. A. Stroud

Further Engineering Mathematics K. A. Stroud 


\section{Elementary \\ Engineering Mechanics}

G. E. Drabble

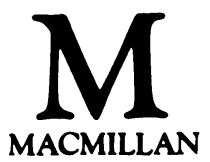


(C) G. E. Drabble 1986

All rights reserved. No reproduction, copy or transmission of this publication may be made without written permission.

No paragraph of this publication may be reproduced, copied or transmitted save with written permission or in accordance with the provisions of the Copyright Act 1956 (as amended).

Any person who does any unauthorised act in relation to this publication may be liable to criminal prosecution and civil claims for damages.

First published 1986

Published by

MACMILLAN EDUCATION LTD

Houndmills, Basingstoke, Hampshire RG21 2XS

and London

Companies and representatives

throughout the world

\section{British Library Cataloguing in Publication Data}

Drabble, G. E.

Elementary engineering mechanics.

1. Mechanics, Applied

I. Title

$531^{\prime} .02462 \quad$ TA350

ISBN 978-0-333-39927-9

ISBN 978-1-349-18322-7 (eBook)

DOI 10.1007/978-1-349-18322-7 


\section{Contents}

Introduction vii

Programme 1: Elementary Statics 1

Equilibrium of two forces 3

Parallelogram law: resultant 4

Resolution: components $\quad 7$

Triangle of forces 9

Polygon of forces $\quad 10$

Exercises: forces acting at a point 20

Moment of a force $\quad 22$

Parallel forces: equilibrium: resultant 26

Centre of gravity $\quad 42$

Mass centre: flat body $\quad 48$

Mass centre: solid body $\quad 54$

Centroid $\quad 63$

Exercises: parallel forces: mass centre: centroid $\quad 70$

Revision exercises $\quad 71$

Programme 2: Elementary Kinematics 75

Displacement: velocity: speed: acceleration $\quad 76$

Velocity-time graph $\quad 83$

Kinematic equations of translational motion $\quad 85$

Exercises: motion in a straight line $\quad 102$

Motion under gravity 104

Exercises: motion under gravity 108

Angular motion: radian 110

Relation between linear and angular kinematics 112

Centripetal acceleration $\quad 125$

Exercises: angular motion: motion in a circular path $\quad 135$

Revision exercises 136

Programme 3: Elementary Kinetics 139

Newton's second law of motion: mass: weight 142

Vehicles: tractive force $\quad 149$

The free-body diagram $\quad 152$

$\begin{array}{ll}\text { Friction } & 158\end{array}$

Motion in a circular path 164

Exercises: dynamics of particles 172

Work: energy: conservation of energy 174 
$\begin{array}{ll}\text { Efficiency } & 175\end{array}$

Kinetic and potential energy $\quad 176$

Power $\quad 184$

Exercises: work, energy and power 186

Momentum: impulse: collision of two bodies 188

Exercises: momentum $\quad 198$

Moment of inertia $\quad 200$

Radius of gyration $\quad 212$

Exercises: moment of inertia: rotating bodies 216

Connected systems $\quad 218$

Exercises: connected systems $\quad 240$

Rigid bodies: vehicles in translation 242

Rigid bodies: vehicles on a circular track 252

Exercises: dynamics of rigid bodies 260

D'Alembert's principle: reversed effective force 262

$\begin{array}{ll}\text { Index } & 267\end{array}$ 


\section{Introduction}

This book comprises a set of three 'programmed texts' designed to help you in learning the fundamental principles of statics, kinematics and kinetics. You may have encountered similar texts elsewhere, but if you have not, you should understand that they are designed to be read, one Frame at a time, in order, without skipping, and without looking ahead at subsequent Frames out of order. Moreover, you should not attempt to work through Programme 3 (Kinetics) until you have thoroughly covered the work of Programmes 1 and 2 (Statics and Kinematics). When working through the texts you might find it helpful to have a card or a sheet of paper, to cover up the Frames ahead of you, so that you do not see answers to any of the questions asked before you have had time to work out the answer yourself. Wherever questions are asked, or exercises set, it is very important that you attempt to answer the questions, or go through the exercises, before reading on; this is how you will learn. If you make any mistakes (and you almost certainly will) you should hopefully find out your errors from the subsequent Frames. Try to understand clearly the reason for your mistake. If you cannot do this, then make a note, and get some help from your lecturer as soon as you get the opportunity.

To work through these texts, you will need

1. A ruler, or draughtsman's scale

2. A protractor

3. A set-square

4. A $2 \mathrm{H}$ (or equivalent) pencil

5. A pen and paper

6. A calculator.

You should get guidance from your lecturers about when you should read these texts, but you should understand that they are designed as revision for A-level or equivalent work, so that ideally, you should have completed working through them before you start on the first year of a Degree course in Engineering. Like most students, you have probably been accepted for a Degree course while feeling that you did not perform as well as you had hoped on your A-levels. You may have been lucky enough to scrape a Grade C in Physics or Applied Mathematics and still have only a very vague notion of centroids, or moments of inertia. Here is a chance to catch up. 